\title{
Fused primary supernumerary tooth associated with maxillary primary lateral incisor: a case report
}

\begin{abstract}
Fusion is a developmental alteration in the shape of teeth and is defined as the dentinal union of two embryologically developing teeth. Supernumerary tooth is an anomaly in the number of teeth and arises due to excessive activation of dental lamina. This paper reports a case of non-syndromic unilaterally fused primary left lateral incisor and supernumerary lateral tooth in the maxillary region.
\end{abstract}

Keywords: fusion, supernumerary tooth, primary dentition
Volume 10 Issue 3 - 2019

\begin{abstract}
Vivek Mehta, Shahnaz Mansoori
Department of Pediatric and Preventive Dentistry, Faculty of Dentistry, Jamia Millia Islamia, India
\end{abstract}

Correspondence: Vivek Mehta, Department of Pediatric and Preventive Dentistry, Faculty of Dentistry, Jamia Millia Islamia, New Delhi, India, Tel +91-92I2024943,

Email drvivekmehtal@gmail.com

Received: December 18, 2018 | Published: May 30, 2019

\section{Introduction}

Fusion is defined as a single enlarged tooth or joined tooth in which the tooth count reveals a missing tooth when the anomalous tooth is counted as one. ${ }^{1}$ It is a dental twinning anomaly and has been described by many terms like double teeth, connated tooth, conjoined teeth or twinned teeth. Clinically, it may appear as normal sized or large, depending upon the stage at which embryological union occurs during development. It is commonly confused with gemination which is an incomplete attempt of one tooth bud to divide into two. The frequency of double teeth in deciduous teeth is greater, with a reported prevalence from 0.5 to $2.5 \%$ and the occurrence is higher amongst Asian populations. ${ }^{1}$ Incisors and canines are the most commonly affected teeth in both dentitions. ${ }^{1}$ Supernumerary tooth arises due to an anomaly in number of teeth due to an excessive dental lamina activity. ${ }^{2}$ Supernumerary teeth occur rarely in the primary dentition as compared to permanent dentition. ${ }^{3}$ The prevalence of supernumerary teeth in primary dentition is $0.2-1.9 \%{ }^{4}$ Males are more commonly affected as compared to females. ${ }^{5} \mathrm{~A}$ frequent finding in fusion of primary teeth is the congenital absence of corresponding permanent teeth. The prevalence of tooth fusion in the primary dentition is 0.5 $2.5 \%{ }^{6}$

\section{Case report}

A seven-year-old girl reported to the Department of Pediatric and Preventive Dentistry with the chief complaint of decayed tooth in the upper arch. The medical history of the child patient was insignificant and there was no family history of dental anomalies. An intraoral examination revealed the presence of complete primary dentition alongwith mandibular permanent first molars and incisors and presence of double tooth in relation to the maxillary left primary lateral incisor (Figure 1). Radiographic examination i.e. OPG revealed that the enlarged bifid crowns were due to fused 62 i.e. maxillary left primary lateral incisor and supernumerary tooth (Figure 2). The diagnosis was fusion caused by union of the maxillary primary left lateral incisor and a supernumerary lateral tooth. Restoration of the primary left lateral incisor and supernumerary lateral tooth was done with glass ionomer cement (GIC) restoration and fused primary teeth were retained (Figure 3). The parents of the child patient gave no history of trauma in the anterior region and consanguineous marriage. A thorough general examination was carried out to rule out the presence of any associated syndrome. The patient was advised to maintain the regular follow-up visits to observe any deviation from normal eruption pattern.

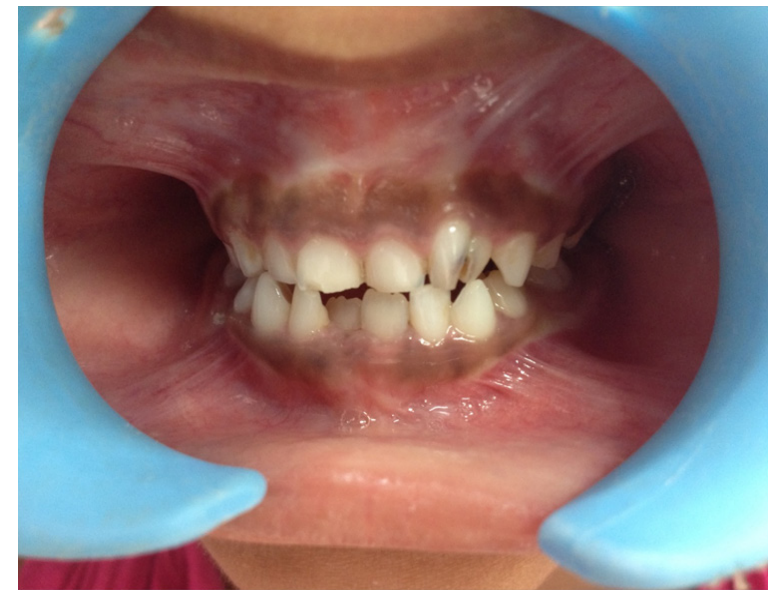

Figure I Preoperative intraoral view presenting two crowns in relation to maxillary primary left lateral incisor.

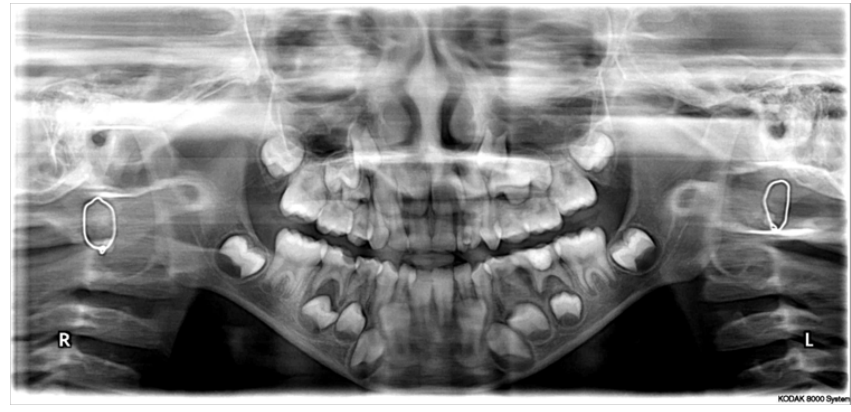

Figure 2 Preoperative OPG showing fused teeth (I). 


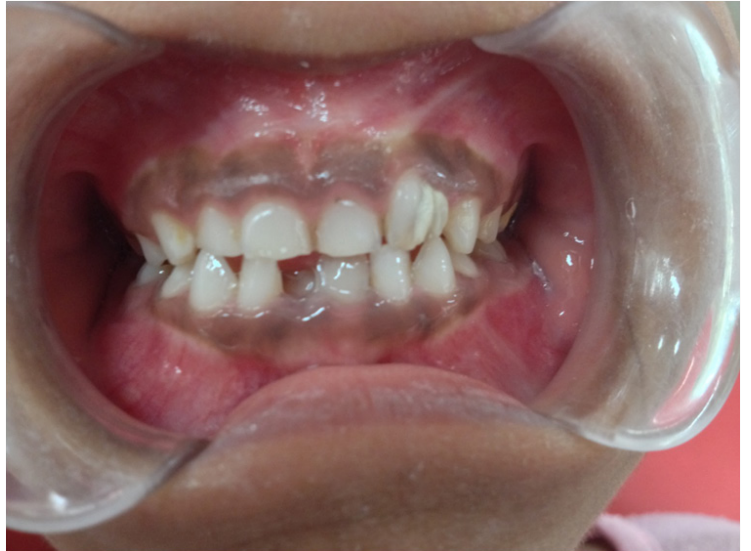

Figure 3 Postoperative intraoral views after restoration of teeth with GIC (2).

\section{Discussion}

Fused teeth arise through union of two normally separated tooth germs and they can be found in almost any region of the dental arch, both in primary and permanent dentitions. According to the most accepted theory, some physical force or pressure is responsible for contact between developing teeth and their subsequent fusion.? Fusion may affect two normal teeth or it may also occur between a normal tooth and a supernumerary tooth which may be a mesiodens or a distomolar. ${ }^{7,9}$ Fusion may be caused by developmental anomalies during the morpho-differentiation stage of the dental lamina and the tooth germ. ${ }^{8}$ Interesting finding of fused supernumerary tooth associated with maxillary lateral incisor in the primary dentition with presence of corresponding permanent tooth makes the present case more extraordinary and worthy to report. The presence of double teeth in the deciduous dentition is associated with crowding, abnormal spacing, and delayed or ectopic eruption of the underlying permanent teeth. ${ }^{1}$ The fissure present at the union between fused teeth predisposes it to dental caries and in some cases periodontal disease. ${ }^{9}$ Fused primary teeth may result in delayed resorption of roots due to its increased root surface area. ${ }^{10}$ This may lead to ectopic resorption of the permanent successor. ${ }^{11}$ The presence of fused teeth in primary dentition has been associated with absence of permanent dentition and the prevalence depends on the combination of fused primary teeth. ${ }^{12}$ Cases of fusion of primary anterior teeth associated with partial anodontia of both primary and permanent dentition ${ }^{13}$ or with anodontia of permanent dentition alone ${ }^{14}$ have also been reported before. The presence of fused teeth can also cause aesthetic problems, especially in the anterior region.

Supernumerary teeth has been associated with a number of syndromes and dental anomalies namely Apert syndrome, Angioosteohypertrophy, Cleidocranial dysplasia, Crouzon syndrome, Curtius syndrome, Down syndrome, Ehler's-Danlos syndrome, Ellis-van Creveld syndrome, Fabry-Anderson syndrome, Gardner syndrome, Hallerman-Streiff syndrome, Leopard syndrome, NanceHoran syndrome, Sturge-Weber syndrome, Tricho-rhino-phalengeal syndrome. ${ }^{1}$ The treatment of fused teeth depends on the clinical situation, patient's expectations and degree of compliance..$^{15}$ Proper instructions regarding maintenance of oral hygiene should be given to the patient to avoid caries. Fissure sealants can be used as they reduce the risk of caries. A multidisciplinary approach can also be used to ensure functional occlusion and aesthetics. In the present case restoration of the primary left lateral incisor and supernumerary lateral tooth was done with glass ionomer cement (GIC) restoration and fused primary teeth were retained as such, as they were free from caries. Preventive approach was planned that included application of topical fluorides and oral hygiene instructions. The child patient was kept under follow-up to observe the pattern of eruption of permanent anterior teeth.

\section{Why this paper is important to Pediatric dentists}

1. Early detection and intervention of fused teeth is essential part of preventive dentistry as it is one of the rare developmental alterations of shape of teeth.

2. A thorough clinical and radiographic evaluation is compulsory as early diagnosis results in enhanced prognosis.

3. Clinically it is challenging to distinguish between fusion and gemination.

4. Early diagnosis of supernumerary tooth in the primary dentition is essential to minimize complications.

5. Fusion of primary teeth may be associated with pulp exposure due to presence of deep grooves.

6. Pediatric dentists should carefully monitor cases of fusion or gemination in primary dentition as in most cases regular and long term follow-up is required.

\section{Conclusion}

This case report presents successful management of a rare case of fused maxillary primary lateral incisor with supernumerary tooth with restorative treatment. The follow-up confirmed a asymptomatic and functional tooth.

\section{Acknowledgments}

None.

\section{Conflict of interest}

The author declares that there is no conflict of interest.

\section{References}

1. Neville BW, Damm DD, Allen CM, et al. Abnormalities of teeth in: Oral and Maxillofacial Pathology. $3^{\text {rd }}$ ed. Elsevier; 2010:77-85.

2. Mohapatra A, Prabhakar AR, Raju OS. An unusual triplication of primary teeth-a rare case report. Quintessence Int. 2010;41:815-820.

3. Yildirim G, Bayrak S. Early diagnosis of bilateral supplemental primary and permanent maxillary lateral incisors: a case report. Eur $J$ Dent. $2011 ;(2): 215-219$

4. Scheiner MA, Sampson WJ. Supernumerary teeth: a review of the literature and four case reports. Aust Dent J. 1997;42:160-165.

5. Shah A, Gill DS, Tredwin C, et al. Diagnosis and management of supernumerary teeth. Dent Update. 2008;35(8):510-512.

6. Prasad Rao VA, Reddy NV, Krishnakumar R, et al. Primary double tooth with partial anodontia of permanent dentition - a case report. $J$ Clini Exp Dent. 2010;2(2):e78-e81.

7. Rajendran R. Developmental disturbances of oral and paraoral structures. In: Rajendran R, Sivapathasundharam B, editors. Shafers Textbook of Oral 
Pathology. $6^{\text {th }}$ ed. New Delhi: Elsevier;2011:39-40.

8. More CB, Tailor MN. Tooth fusion, a rare dental anomaly: analysis of six cases. International. J Oral Maxillofac Pathol. 2012;4(1):50-53.

9. Nunes E, de Moraes IG, de Oliviera Novaes PM, et al. Bilateral fusion of mandibular second molars with supernumerary teeth: Case report. Braz Dent J. 2002;13:137-141.

10. Brook AH, Winter GB. Double teeth. A retrospective study of 'geminated' and 'fused' teeth in children. Br Dent J. 1970;129(3):129-310.

11. Gelin ME. The distribution of anamolies of primary anterior teeth and their effect on the permanent successors. Dent Clin North Am. 1984;28(1):69-80.

12. Tsujino K, Yoneju T, Shintani S. Effects of different combinations of fused primary teeth on eruption of permanent successors. Pediatr Dent.

\section{3;35(2):E64-67.}

13. Mehta V. Fusion of primary mandibular anterior teeth associated with partial anodontia of primary and permanent dentition: A Case Report. $J$ Dent Health Oral Disord Ther. 2015;3(3):00090.

14. Mehta V. Fusion of primary mandibular teeth associated with partial anodontia of permanent dentition: A case report. Int J Oral Max Pathology. 2015;6(1):23-25.

15. Sekerci A, Sisman Y, Ekizer A, et al. Prevalence of double (FusedGeminated) primary teeth in Turkey- A study. Pak Oral Dent J. 2011;31(1):7-13. 